Arteterapia. Papeles de arteterapia y educación para inclusión social ISSN-e 1988-8309

https://dx.doi.org/10.5209/arte.62572

\title{
Arte, cuerpo e identidad para una investigación-acción participante con estudiantes afrodescendientes
}

\author{
Ana Cebrián Martínez ${ }^{1}$, Patricia Rocu Gómez²
}

Recibido: 24 de enero de 2019 / Aceptado: 10 marzo 2019

Resumen. Afronteriz*s es un programa de co-aprendizaje (entre arteeducadoras y educadoras de la comunidad afrodescencendiente y estudiantes de secundaria), un grupo de investigación-acción y práctica colaborativa que surge en 2016 en el Centro de Residencias Artísticas de Matadero Madrid.(*) La educación es una herramienta esencial para la consecución de una sociedad en la que las diferencias no sean percibidas como algo negativo y donde no se invisibilicen las problemáticas que se dan desde los planteamientos multiculturalistas tales como: negación del racismo institucional, invisibilización de los conflictos estructurales, categorización de la diversidad obviando la realidad interseccional y de conciencia mestiza (Anzaldúa, 2004)). Reconocemos la necesidad de una educación transcultural (Onghena, 2014; Ortiz, 2002), en la cual la diversidad que vemos cada día en nuestras calles pase a formar parte de los planes de estudio de los diferentes niveles del sistema educativo español. Es por ello que con este estudio aproximativo queremos abordar los resultados obtenidos a partir del trabajo con referentes racializados, el pensamiento crítico, el trabajo con el cuerpo y la identidad o el análisis del arte y la cultura visual. Presentamos un estudio de caso en el aula de $3^{\circ}$ de la E.S.O PMAR del IES PRADOLONGO, en el distrito de Usera (Madrid). Los talleres llevados a cabo han demostrado ser un refuerzo de la autoestima de los estudiantes, proporcionándoles mejores herramientas para el análisis de su realidad social, favoreciendo sus posibilidades de inclusión, empoderamiento y desarrollo personal, lo que les permite actuar como mediadores para la prevención de los conflictos que puedan iniciarse en el contexto del aula-centro educativo.

*El grupo Afronteriz*s es un proyecto surgido del Espacio ConcienciaAfro, grupo de pensamiento del Centro de Residencias Artísticas de Matadero Madrid. Es coordinado por Ana Cebrián y está compuesto por los siguientes miembros: Ana Cebrián, Patricia Rocu, Yeison García López, Yos Piña, Sara Martín López, Sheherezade F. Shephard. y Victoria Cupe. Se ha publicado un material didáctico (ISBN: 97884-09-03769-8) editado por Matadero Madrid, donde se relatan con detalle los talleres desarrollados en el IES PRADOLONGO.

Palabras clave: educación transcultural; co-aprendizaje; pensamiento crítico; inclusión social; desarrollo personal.

\section{[en] Art, body and identity for a participatory action research with afro-descendant students}

Abstract. Afronteriz*s is a co-learning program (between art educators and educators of the Afrodescendant community and high school students), a collaborative action-research group that emerged in

1 Profesora de la Facultad de Educación de la Universidad Complutense de Madrid. Departamento de las Lenguas, las Artes y la Educación Física.

E-mail: anacebri@ucm.es

2 Profesora de la Facultad de Educación de la Universidad Complutense de Madrid. Departamento de las Lenguas, las Artes y la Educación Física y profesora de la Facultad de Ciencias de la Actividad Física y el Deporte de la Universidad Politécnica de Madrid.

E-mail: p.rocu@edu.ucm.es 
2016 at the Artistic Residency Center of Matadero Madrid. Education is an essential tool for achieving a society in which differences are not perceive as something negative and where the problems that arise from multiculturalist approaches are not made invisible such as: denial of institutional racism, invisibility of structural conflicts, categorization of diversity, avoiding the intersectional reality and mestizo consciousness (Anzaldúa, 2004). We recognize the need for a cross-cultural education (Onghena, 2014; Ortiz, 2002), in which the diversity that we see every day in our streets becomes part of the curricula of the different levels of the system Spanish education. That is why with this close study we want to approach the results obtained from the work with racialized references, critical thinking, work with the body and identity or the analysis of art and visual culture. We present a case study in the 3rd classroom of the E.S.O PMAR of IES PRADOLONGO, in the district of Usera (Madrid). The workshops carried out have proven to be a reinforcement of the students' self-esteem, providing them with better tools for the analysis of their social reality, favoring their possibilities of inclusion, empowerment and personal development, which allows them to act as mediators for the prevention of the conflicts that can begin in the context of the classroom-educational center.

Keywords: transcultural education; co-learning; critical thinking; social inclusion; personal development.

Sumario. Introducción y contexto. 1.1. Arte, cuerpo y educación: estrategias para el desarrollo personal, empoderamiento e inclusión social del alumnado afrodescendiente y no afrodescendiente. 1.2. Contenidos: cultura visual, contranarrativas, poder y referentes. 2. Proceso metodológico. 2.1. Características de la investigación. 2.2. Participantes 2.3. Programa de co-aprendizaje. 2.4. Instrumentos. 2.5. Procedimiento. 3. Resultados. 3. 1. Percepciones del cuerpo racializado desde la cultura visual. 3.2. Percepciones del cuerpo racializado desde el ámbito educativo. 3.3. La propuesta educativa. 4. Conclusiones. 5. Referencias bibliográficas.

Cómo citar: Cebrián Martínez, A. Rocu Gómez, P. Arte, cuerpo e identidad para una investigación-acción participante con estudiantes afrodescendientes en Arteterapia. Papeles de arteterapia y educación para inclusión social 14, 2019, 113-129.

\section{Introducción y contexto}

\subsection{Arte, cuerpo y educación: estrategias para el desarrollo personal, empoderamiento e inclusión social del alumnado afrodescendiente y no afrodescendiente}

Actualmente existen un máximo de 1.600 .000 de afrodescendientes en nuestro país, según las cifras aportadas por el historiador panafricanista Antumi Toasijé (Blakely, 2012). Entre toda la gran cantidad de asociaciones y colectivos de la comunidad afro en España, muchos ponen el foco en la importancia de la educación. La educación es uno de esos lugares donde se crean nuevos ciudadanos, donde la diversidad es un hecho, donde convivimos, donde rechazamos profundamente cualquier acto discriminatorio o abusivo. Donde debemos educarnos como personas capaces de amar y respetar incluso a quien no comprendemos, a quien creemos diferente o con ideas o culturas que no nos son propias. Creyendo firmemente en las aulas como piezas clave para avanzar en el entendimiento y el respeto mutuo, desde Afronteriz*s se ha trabajado en la implementación de una serie de talleres en colegios e institutos, con la esperanza de animar a las instituciones a participar activamente en este tipo de proyectos.

A continuación presentamos los resultados de la experiencia desarrollada con los estudiantes de un aula de $3^{\circ}$ de la E.S.O PMAR del IES PRADOLONGO en el distrito de Usera, un proyecto de cuatro sesiones en las que participó estudiantado 
afrodescendiente, racializado y no racializado, la docente y la psicóloga social del centro, además de nuestro equipo de co-aprendizaje.

A partir de esta experiencia se pretende iniciar una conversación en torno a la imagen de la afrodescendencia en nuestro sistema educativo, reflexionar sobre cómo los estereotipos negativos, activos en nuestra cultura visual, generan imaginarios que desencadenan violencias cotidianas (Sos Racismo, 2017). Proponemos una toma de conciencia a partir del análisis crítico de las imágenes para un mayor conocimiento de las actitudes discriminatorias, y una mayor conciencia del cuerpo y la identidad como focos del empoderamiento y desarrollo personal del estudiantado afrodescendiente y racializado, incidiendo así también, en el resto de la comunidad educativa. En esta alianza entre disciplinas: arte, cuerpo y educación surge esta propuesta.

\subsection{Contenidos: cultura visual, contranarrativas, poder $y$ referentes}

No hay información más inmediata que la que proporciona una imagen, es por esto que se ha trabajado con arte y acción corporal, porque es la imagen de los afrodescendientes la que se vulnera y se utiliza para generar un conocimiento erróneo que hace que la población opere desde lógicas que derivan en conflicto, discriminación y exclusión. Desde un clima de confianza construida poco a poco, del reconocimiento de nuestra diferencia y especificidad; a lo largo del proyecto se ha generado un espacio donde compartir emociones y sensibilidades en torno a temáticas tan significativas como: el racismo en la cultura visual, la escasez de referentes racializados en el currículo escolar o la importancia de las estrategias de co-aprendizaje para abordar los conflictos que puedan suceder en el aula. A partir de la realización de diferentes talleres con artistas y educadores se profundizó en la creación de contranarrativas que denunciaran y desmontaran dichos estereotipos, generando alternativas creativas basadas en la obra de los artistas afrodescendientes contemporáneos (Cebrián, 2015) o la imagen de referentes históricos y actuales de la cultura afro (Antoine, 2014; Serbin 2017).

Se comenzó reflexionando sobre aquellas circunstancias de racismo cotidiano que se dan habitualmente durante el uso del transporte público, los espacios de consumo, los estereotipos al relacionarse entre amigos o ligar, desde el cuestionamiento crítico de los principales productos de consumo mediático: racismos corporales, actitudinales y profesionales. Se organizaron tres pequeños grupos para poder conversar desde la cercanía y la confianza para expresar emociones, puesto que es un tema que con frecuencia produce rabia o dolor. Tras reconocer un sentimiento de impotencia para hacer frente a toda esa información lanzada desde los medios de comunicación de masas, se exploraron algunas alternativas surgidas de las mismas voces racializadas. A través del collage y la recontextualización se escenificanron contranarrativas, dando la vuelta a los discursos sobre los roles estereotipados que se les asocian tanto a las personas racializadas como a las personas blancas.

Se pretendía que los estudiantes reflexionaran desde la producción de contenidos, de modo que se introdujo un tema fundamental para nuestro trabajo educativo: la necesidad de referentes positivos que representen a las comunidades racializadas que encontramos en el aula. A través de fotografías con figuras de diferentes épocas y campos del saber, acompañados de citas que sirvieran como marco para su presentación, y que posteriormente, se utilizaron en un ejercicio corporal. Para lograr empoderarnos desde un sentimiento de comunidad que permitiera a los estudiantes 
cuestionar los currícula oficiales en sus carencias relativas a la representación de la diversidad, se reforzaron visiones "otras" que nos instruyaeran sobre la puesta en marcha de alianzas y fertilizaciones cruzadas. Con este fin, a través de tres palabras: LIBERTAD, PODER Y UNIÓN, se inició una dinámica corporal para enfatizar movimiento y sonido como proceso de interacción simbólica.

En otra de las sesiones, se contactó con referentes racializados, personas accesibles que querían compartir con los estudiantes sus distintas experiencias educativas, así como sus propias historias de cómo habían llegado a situarse en su carrera profesional. Así, ese día nos acompañaron Angélica Dass (artista-fotógrafa), Antumi Toasijé (historiador-educador-activista), Rita Bosaho (política), Patricia Rocu (profesora universitaria), Sofía Perdomo (actriz-diletante), Will J. Shepard (actor) y Lamine Thior (actor). Que se compartieran experiencias con miembros de la propia comunidad fue un vehículo para sentirse reconocidos más allá de los estereotipos. Igualmente, ayudó a todos a imaginar múltiples posibilidades de futuro, al tiempo que se sincerarban desde la comprensión mutua, el apoyo y el refuerzo positivo de lo que somos.

A lo largo de las sesiones, los estudiantes y la docente fueron tomando la palabra, se dejó espacio para recoger las opiniones y favorecer la participación desde el respeto a las distintas opiniones, buscando poner en conexión unos y otros discursos. Se abrieron muchas conversaciones que nos sacudieron a todos por las potencialidades empoderadoras que tiene verse reflejado en rostros que consiguieron/consiguen cambiar el curso de la historia, denunciar situaciones de injusticia, ser valientes, descubrir, crear, ayudar a otros, ejemplo de lucha y creatividad para todos. Así, se continuó con la conversación, tratando de resolver en conjunto varias cuestiones que podían preocuparnos: ¿Cuáles eran nuestras metas? ¿Qué nos impedía lograrlas? ¿Qué queríamos hacer y cómo podíamos conseguirlo?

Los artistas afrodescendientes, educadores y aliados, proponen otras lecturas, otros imaginarios, otras representaciones, que nos devuelven preocupaciones y paisajes muy distintos de los actuales, capaces de ofrecer soluciones alternativas, conversaciones no abordadas aún, que modifiquen los escenarios para seguir operando, esta vez sí, desde una óptica transcultural, donde la propia comunidad sea protagonista, donde todos podamos construir posibilidades transformativas.

\section{Proceso metodológico}

\subsection{Características de la investigación}

El estudio se abordó desde una perspectiva de investigación dentro del paradigma cualitativo. De manera concreta se empleó la Investigación Acción Participante (IAP) cuyo enfoque se centra en la resolución de problemas de los grupos estudiados a partir del desarrollo, concienciación y una autonomía propia como grupo (Martínez, 2000). En la investigación que se presenta se concedió una máxima importancia a la interacción entre todas las personas participantes. Alumnado, profesora y educadoras del equipo de Afronteriz*s se configuraron como un todo desde una perspectiva en la que por parte de todos los agentes implicados se co-aprende, se experimenta, se reflexiona y se comparten vivencias, registrando todas las voces durante el proceso.

La intención propuesta fue analizar y comprender la situación particular objeto de estudio desde la perspectiva de todas las personas que han intervenido en el proceso 
de interacción educativo. Se llevó a cabo una observación participante, teniendo siempre en cuenta que la información es recogida desde la perspectiva de las personas que se encargaron de dinamizar las actividades implementadas en el proceso educativo.

\subsection{Participantes}

Participó un grupo de 25 estudiantes de $3^{\circ}$ de la ESO y su profesora del área de Música. El alumnado se caracterizó por ser un grupo muy diverso desde un punto de vista étnico-racial en el que se incluían personas racializadas pertenecientes a la comunidad, latina, gitana y afrodescendiente así como personas migrantes y no migrantes. Ni profesora ni alumnado habían participado nunca de acciones educativas en las que se trabajase la identidad étnico-racial para empoderar a las personas racializadas por lo que carecían de experiencias previas en este sentido.

\subsection{Programa de co-aprendizaje}

La intención del programa, teniendo en cuenta al alumnado participante, perseguía el desarrollo de las diferentes capacidades de la persona, y que aprendieran no solo los conceptos asociados a la temática trabajada, sino que, y, sobre todo, fuesen capaces de alcanzar un pensamiento crítico a través de la reflexión. Además, también se pretendía que el aprendizaje recayese en todas las personas que participaban y no solo en el alumnado.

Se pretendía que adquiriesen el conocimiento de una serie de estrategias básicas para una buena gestión de conflictos surgidos del racismo a partir de la toma de conciencia de las múltiples situaciones, en diversos contextos y desde la primera persona. A partir de este deseo, concretamos los siguientes objetivos de taller para los estudiantes:

- Detectar estereotipos, prejuicios y actos discriminatorios racistas.

- Adquirir herramientas para una gestión adecuada de los conflictos que permita afrontar y denunciar las agresiones.

- Reflexionar sobre las distintas formas de construir las identidades y ser conscientes de las diferencias que existen entre la identificación que realiza la sociedad y cómo nos identificamos personalmente.

- Conocer la existencia de referentes racializados y su contribución principal a la sociedad.

Como objetivos específicos para los estudiantes racializados:

- Empoderarse como parte de una colectividad con capacidad de apoyo.

Como objetivos específicos para los estudiantes no racializados:

- Empoderar la diversidad dentro de la propia comunidad educativa.

Al considerar todo lo expuesto hasta ahora los objetivos de investigación que se plantearon en este estudio fueron los siguientes: 
- Conocer la percepción del alumnado en torno a los procesos vitales respecto de la racialización y afrodescendencia.

- Analizar y evaluar la propuesta educativa implementada en el aula, identificando tanto los puntos fuertes como aquellos que hemos de mejorar.

Las sesiones mantuvieron una estructura común: una parte introductoria, en la que se realizaba una exposición inicial de lo que se iba a tratar ese día; una segunda parte, en la que se llevaban a cabo las actividades principales acordes a los objetivos de sesión propuestos; finalmente, en la última parte se hacía una puesta en común sobre todo lo trabajado que se quisiera tratar y/o exponer como opinión personal. Se desarrollaron un total de 4 talleres en los que se abordaron los siguientes contenidos en cada sesión:

- Sesión 1: Presentación - toma de contacto

- Sesión 2: Racismo y cultura visual: contranarrativas desde el arte

- Sesión 3: Referentes históricos, cuerpo e identidad

- Sesión 4: Referentes actuales y empoderamiento

\subsection{Instrumentos}

Para la recogida de datos se utilizaron diferentes instrumentos de manera que todas las personas participantes pudieron manifestar sus percepciones, valoraciones y opiniones desde su punto de vista. Los instrumentos empleados fueron:

- Una Unidad Didáctica relatada a través de la que se recogieron todas las intenciones educativas y el desarrollo diario de las mismas de forma narrativa.

- El Diario Grupal de los componentes del equipo Afronteriz*s en el que se recogía la reflexión conjunta de los registros obtenidos a través de grabadora y también se exponían las observaciones realizadas de todo lo acontecido en el transcurso de las sesiones procedentes de reuniones y conversaciones mantenidas entre los diferentes participantes (entre educadores, educadores y alumnado, entre el alumnado y entre educadores y profesora).

- Diario individual en el que se recogían las percepciones personales de los miembros del equipo Afronteriz*s.

- Y una Relatoría en el que quedaba reflejada la percepción del alumnado.

\subsection{Procedimiento}

Se contactó en primer lugar con el centro educativo y se solicitaron los permisos necesarios (la autorización de la Dirección del centro, así como la de familiares del alumnado) para poder realizar fotografías y participar en la investigación. Al inicio de la implementación del programa se explicó al alumnado las intenciones del mismo y se les dio la oportunidad de participar activamente en cualquier momento. Conforme avanzaba la dinámica, se fue recogiendo la información a analizar mediante los instrumentos ya señalados anteriormente.

Considerando que se empleó como estrategia metodológica la IAP, como equipo, tuvimos que compartir conocimientos e informarnos más sobre otras comunidades racializadas en España presentes en el aula, como la comunidad gitana o la pro- 
cedente de América Latina y el Caribe, y reelaborar tanto los materiales como los contenidos de los talleres.

La Unidad Didáctica, El diario grupal y el Diario Individual fueron desarrollados fuera del horario lectivo, mientras que la Relatoría se recogía a través de anotaciones durante el transcurso de las sesiones. Toda la información se fue incorporando a un documento de Word colaborativo en línea en Google Drive, de manera que el equipo de Afronteriz*s estaba al corriente de toda la información conjunta.

Una vez recopilada toda la información, a través del programa informático Atlas. ti versión 7 se analizaron todos los datos, cuyos resultados se exponen en el epígrafe posterior.

\section{Resultados}

\subsection{Percepciones del cuerpo racializado desde la cultura visual}

La ilusión, la implicación y la participación diversa en este programa, en tanto en cuanto se es sensible a los procesos vitales racializados, ya sean vivenciados o no en primera persona, reconocidos o no reconocidos, comprendidos o no desde las diferentes perspectivas, se configuran, junto a una intencionalidad basada en el co-aprendizaje de todos los miembros que participan en esta experiencia educativa como los ejes vertebradores que impulsan todo el proceso:

"Ilusionadas, el equipo de Afronteriz*s nos encaminamos al centro. Vamos Yos, Victoria, Ngoy, Yeison, Sara y yo. Todxs estamos nerviosas, llenas de emoción por comenzar los talleres: creemos que podemos cambiar cosas, que un grupo de estudiantes a lxs que se acostumbra a etiquetar hoy pueden salir de clase sintiéndose un poco más poderosxs.

(...) Preferíamos, por contra, contarte lo sucedido desde nuestras propias voces (que son disonantes, habitadas, personales, politicas) y hablar de lo que hemos sentido desde diferentes opciones y lugares; entendemos, también, que estas sesiones parten de consensuar los procesos en el aula, de buscar y probar, de decidir entre todxs vuestra participación y adaptar todo lo que no os funcione a vuestra circunstancia concreta." (Ana)

El punto de partida es la identificación mutua entre el alumnado y el equipo de Afronteriz*s de lo que implica tener un cuerpo racializado desde la comprensión y el entendimiento recíproco. No obstante, se tenían ciertas dudas sobre si estarían preparados para hablar sobre una temática tan íntima y serían capaces de desvelar sus experiencias discriminatorias abiertamente en el aula:

"No estábamos segurxs de si romperían la barrera de la desconfianza, de si el racismo sería un tema sobre el que todavía no desearían posicionarse; tampoco podiamos saber si estarían dispuestxs a contarnos sus propias experiencias y hablar desde su dolor o su rabia." (Unidad Didáctica) 
No obstante, desde el punto de vista de los miembros del equipo de Afronteriz*s, por experiencia propia, se tenía la certeza de que el diálogo entre iguales originado desde una misma perspectiva de todas estas cuestiones permitiría empoderar al alumnado e identificarse en la sociedad más allá de los estereotipos presentes en la mirada hegemónica sobre las personas racializadas:

"Desde nuestra posición, consideramos que compartir nuestras experiencias con miembrxs de nuestra comunidad es un vehículo para sentirnos reconocidxs más allá de los estereotipos. Igualmente, nos ayuda a todxs a imaginar múltiples posibilidades de futuro, al tiempo que nos da pie a sincerarnos desde la comprensión mutua, el apoyo y el refuerzo positivo de lo que somos." (Unidad Didáctica)

No obstante, desde los estereotipos inmersos en la cotidianidad, así como en la cultura visual contemporánea, se articuló el planteamiento de las actividades a partir de las cuáles el alumnado reconoce la presencia de racismo en diferentes ámbitos y contextos de la sociedad. Desde estas opiniones del grupo en torno a las imágenes analizadas, y sobre las que se ha reflexionado durante el desarrollo de las actividades del aula, se identifican comentarios como los siguientes:

\section{Racismo en los medios:}

Respecto a las imágenes en las que se muestra el "Black Face" o disfraz de persona negra como una representación exagerada de los rasgos fenotípicos afro mediante la hipérbole de algunas de sus características físicas, como unos labios muy gruesos y muy rojos o piel exageradamente negra entre otras, el alumnado expone comentarios que se corresponden con el estereotipo hegemónico sobre las personas negras (sin civilizar y culturalmente más arcaicas), que van desde un análisis objetivo del significado de lo que representa la imagen (Figura 1), pasando por la emisión de un juicio reprobatorio al considerar que lo que se busca es ridiculizar a las personas negras y por lo tanto es ofensiva, e incluso la predicción de lo que ocurriría en caso de que se produjese la situación inversa en la representación exagerada de personas blancas.

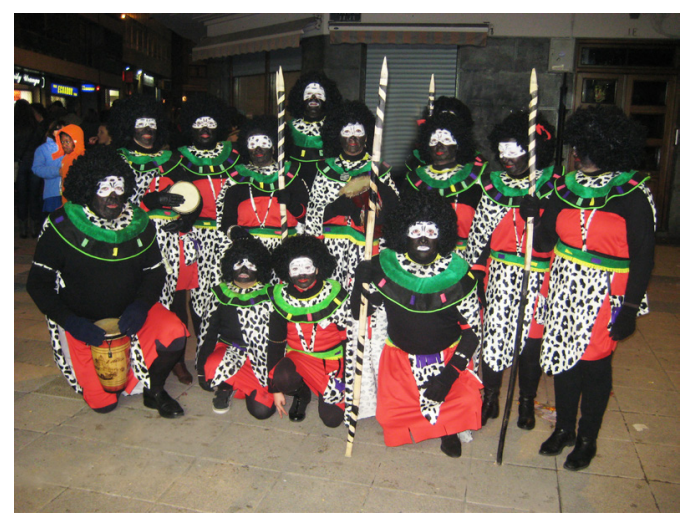

Figura 1. Blackface, acción de disfrazarse de personas negras por parte de un grupo de personas blancas, recurriendo a clichés y estereotipos. 
"La imagen de la tribu muestra que las personas menos civilizadas suelen ser negros" (Alumnado grupo 1).

"Es ridículo, están vestidos así y están en una ciudad, en una calle. Eso es un tipo de burla. Se disfrazan, así como si fuesen un chiste.” (Alumnado grupo 3)

“'Y si yo me quiero disfrazar de blanco? ¿Existe un disfraz de blanco? Si voy a una tienda de disfraces y pido un disfraz de negro, me sacan un disfraz, y si pido un disfraz de persona blanca ¿eso existe? El vendedor se reiría.” (Alumnado grupo 3)

Resulta interesante comprobar cómo este tipo de imágenes asociadas al hecho de disfrazarse de personas negras resultan inofensivas para muchas personas no racializadas, circunstancia que queda manifiesta en la experiencia de un miembro del equipo con un grupo de estudiantes universitario que cursa estudios de Grado en Maestro de Educación:

“También me resultó curioso ver cómo en los tres grupos costaba identificar que la imagen en la que aparecía una tribu negra era, en realidad, un grupo de personas blancas disfrazadas. Todxs lxs estudiantes negrxs mostraron su desacuerdo al tener que presenciar este tipo de escenas, expresando que les causaban malestar. Este hecho me pareció muy significativo, especialmente en comparación personal con varios grupos de universitarixs blancxs con los que reflexionamos aquella misma semana no valoraron el llamado "blackface" como algo ofensivo para la comunidad negra." (Patricia)

Por otro lado, en alguna de las imágenes sobre las que el alumnado reflexionó, no identificaron como racistas ni que reprodujeran ningún estereotipo, y, por lo tanto, no eran ofensivas. Tal es el caso del spot publicitario de los "Conguitos" (Figura 2). También queda manifiesto que hay un desconocimiento de la realidad histórica y del significado completo de la imagen que representan los personajes, por lo que es lógico pensar que el alumnado no tenga una visión tan crítica en este caso:

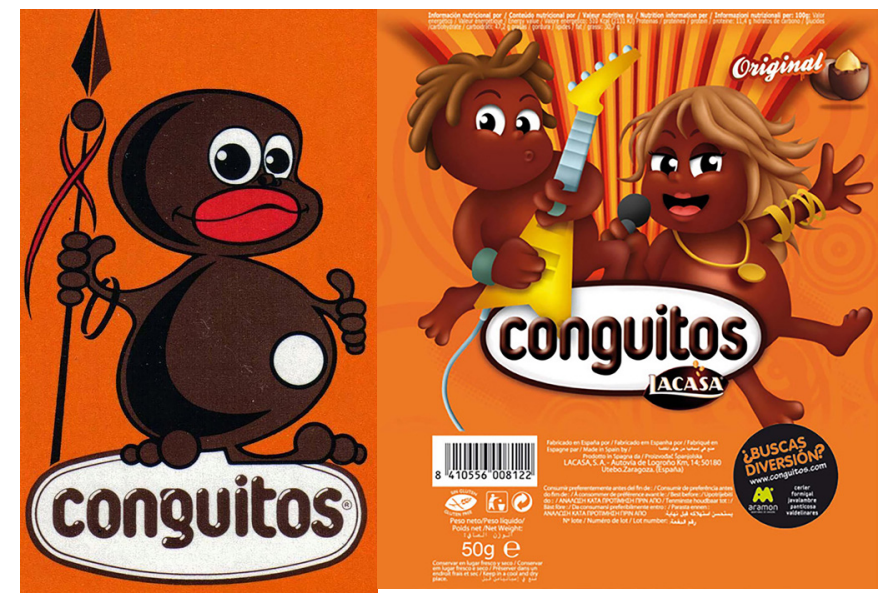

Figura 2. Evolución del anuncio de Conguitos. 
"No me había dado cuenta que "conguito" hace referencia al Congo. Por los labios gruesos del "Conguito” cuando vi el anuncio por primera vez, pensaba que era algo picante." (Alumnado grupo 1)

"Los "Conguitos" son de chocolate, es normal que los pongan marrones. No me parece racista. "(Alumnado grupo 3)

También se identifican los clichés asociados al canon de belleza que predomina en la sociedad actual, el cual resulta más bello cuanta mayor similitud tenga con el cuerpo no racializado. Se reconoce también la sexualización de las personas negras (Figura 3), adoptando unos matices diferentes en el caso de la mujer con respecto al hombre:

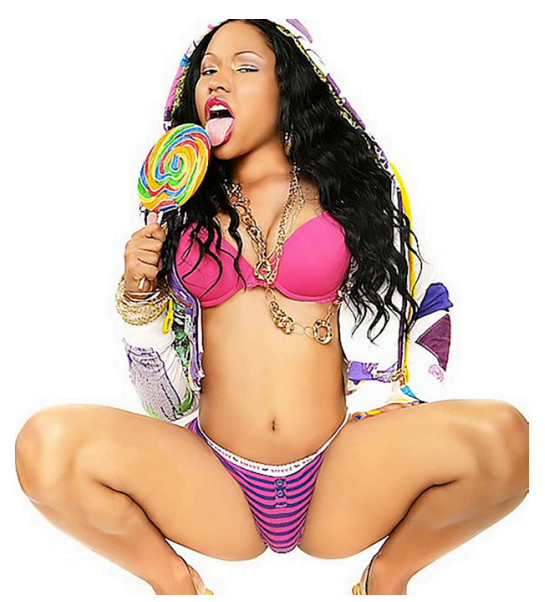

Figura 3. Nicky Minaj (cantante). Personificación de la imagen hipersexualizada de las personas negras en el mundo de la música.

"Las negras y mulatas son mujeres fáciles. Siempre están con posturas provocadoras." (Alumnado grupo 1)

“Las poses son muy sexuales y todas tienen buen cuerpo" (Alumnado grupo 2)

"Las personas negras son vistas como objetos sexuales" (Alumnado grupo 3)

\section{Racialización de las profesiones:}

El análisis del alumnado sobre la imagen social que tienen las personas negras y racializadas vinculada a las profesiones tiene connotaciones negativas ampliamente reflejadas a través del cine, por ejemplo, el mundo de las drogas o la violencia, tal y como se muestra en los siguientes comentarios de grupo:

"Llena de prejuicios de que los colombianos son trabajadores de la cocaína" (Alumnado grupo 3)

“Degradación del latinoamericano" (Alumnado grupo 2)

“Profesión maletero.” (Alumnado grupo 2) 
De la misma manera, las creencias que asocian el desarrollo de las capacidades físicas (fuerza, potencia, resistencia...) como cualidad relevante de las personas negras frente a las capacidades intelectuales (Figura 4), favorece que se expresen comentarios como lo siguientes:

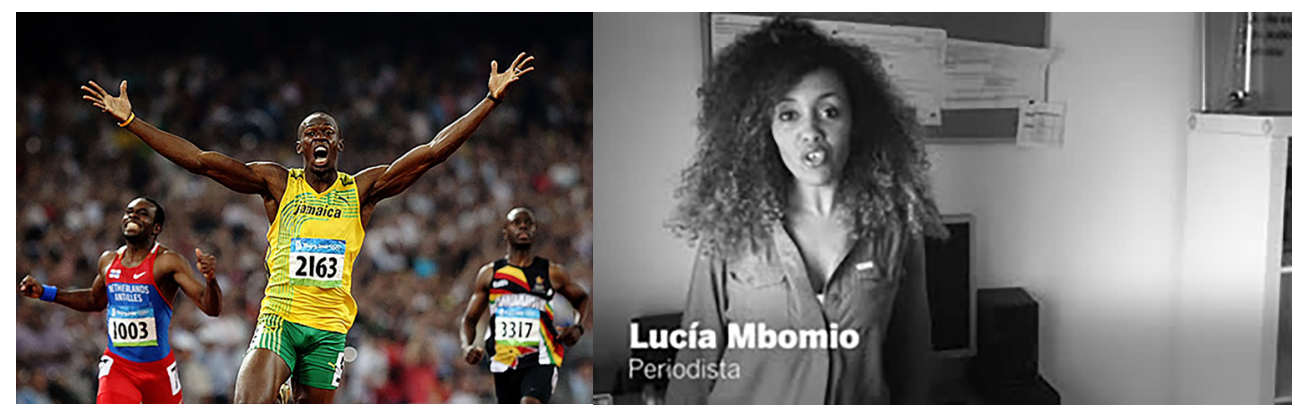

Figura 4. Sobrerrepresentación de personas negras en el ámbito deportivo en comparación a la infrarrepresentación en otro tipo de profesiones. Usain Bolt (atleta),

Lucía Asué Mbomío, (periodista de RTVE).

"Se les clasifica directamente como buenos deportistas por ser negros." (Alumnado grupo 1)

“Los negros tienen más fuerza.” (Alumnado grupo 2)

"No es usual ver gente negra en la televisión, pero sí en los deportes." (Alumnado grupo 3)

Del análisis y reflexiones emergentes del desarrollo de estas sesiones se consigue alcanzar un clima seguro y de confianza para todas las personas participantes al tiempo que se pretende invertir el estado emocional que de todo ello se desprende:

"Esta fase de reflexión es muy importante para desmitificar nuestras concepciones y deconstruir los estereotipos que hemos interiorizado.

Frente a la denuncia de esta realidad, lxs estudiantes se sienten en confianza para expresar sus emociones; tras reconocer un sentimiento de impotencia para hacer frente a toda esa información lanzada desde los medios de comunicación de masas, exploramos algunas alternativas en positivo que hagan frente a la desinformación desde narrativas surgidas de las mismas voces racializadas." (Unidad Didáctica)

\subsection{Percepciones del cuerpo racializado desde el ámbito educativo}

Posteriormente al desarrollo de las actividades se reflexionó sobre los planteamientos pedagógicos de las diferentes asignaturas, los contenidos del currículo y su enfoque hacia la diversidad étnico-racial, se exponen aquí las intenciones educativas que se perseguían alcanzar: 
"Nos interesa, a lo largo de esta dinámica, lograr empoderarnos desde un sentimiento de comunidad que permita a lxs estudiantes cuestionar los currícula oficiales en sus carencias relativas a la representación de la diversidad. Así pues, trabajamos aquí para construir y reforzar visiones otras que nos instruyan sobre la puesta en marcha de alianzas, fertilizaciones cruzadas y cimarronías." (Unidad Didáctica)

La percepción de una imagen distorsionada de las personas racializadas, así como su ausencia en el sistema educativo en general y en los libros de texto en particular son el reflejo de un sentir colectivo en el grupo, tal y como muestra uno de los miembros del equipo de trabajo:

"Acaso demasiado a menudo parece que no existimos, que no hemos hecho nada por la humanidad, que somos un invento reciente o que nuestra historia está ligada únicamente a la esclavitud o a ser seres errantes. Los libros de texto lo refuerzan, no incluyéndonos por ninguna parte como personalidades influyentes. Estaba nerviosa porque yo pensaba en mi Yo del pasado y no sabía si a lxs chicxs les haría la misma ilusión que a mí." (Victoria)

Para abordar estas temáticas y en contraposición al planteamiento anterior basado en el análisis de imágenes visuales con connotaciones negativas se dio visibilidad a diferentes figuras racializadas que favorecieran la deconstrucción del imaginario hegemónico de estas personas. Se trataba, por un lado, de figuras referentes de cierta relevancia desde un punto de social, cultural y/o histórico (Figura 5), y, por otro lado, otros más cercanos dentro del contexto español, con los que poder identificarse y alejados de los estereotipos habituales:

"Dentro de estas dinámicas, consideramos importante retomar periódicamente la ampliación de figuras africanodescendientes y/o racializadas de referencia, en un contexto de deconstrucción creativa de los imaginarios racistas utilizados en la fase anterior. Todo ello podemos visionarlo en la próxima sesión." (Unidad Didáctica)

"El hecho de traer a referentes de carne y hueso era para nosotras una prioridad dentro del desarrollo del taller; desde mi posición situada, como chaval negro que ha crecido en España, nunca tuve actividades de este tipo en mi colegio. Los referentes afro en mi vida eran siempre los mismos: futbolistas.

Para mí, es fundamental ampliar el campo de representación de lo negro. Años atrás, me sentía atrapado en la cárcel de la representación del otro: era el negro malo, futbolista o pandillero. No fue sino al salir de la adolescencia cuando empecé a romper con algunos de los estereotipos que, notaba, recaían en mí, sin que pudiera entender muy bien por qué." (Yeison)

Respecto a los primeros referentes, quedó manifiesto que el alumnado no identificaba a muchos de los personajes racializados que se les mostraron con los que podrían identificarse y construir su identidad: 
"La mayor parte de lxs alumnxs desconocian a lxs personajes, lo cual hizo preguntarles por qué, a pesar de su importancia, no hallan lugar en nuestro currículum escolar, o los motivos por los que se silencia o niega el carácter racializado de figuras célebres, como Alejandro Dumas o la Reina Tiy." (Afronteriz*s)

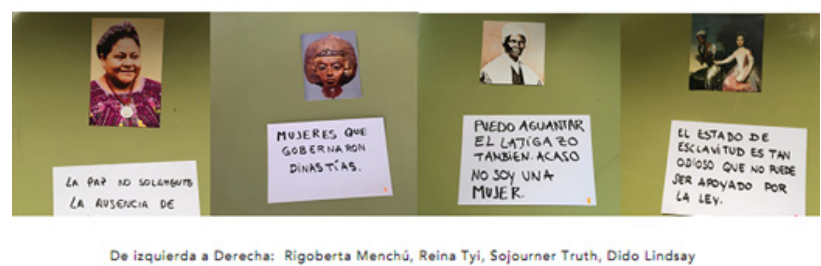
Elizabeth Belle.
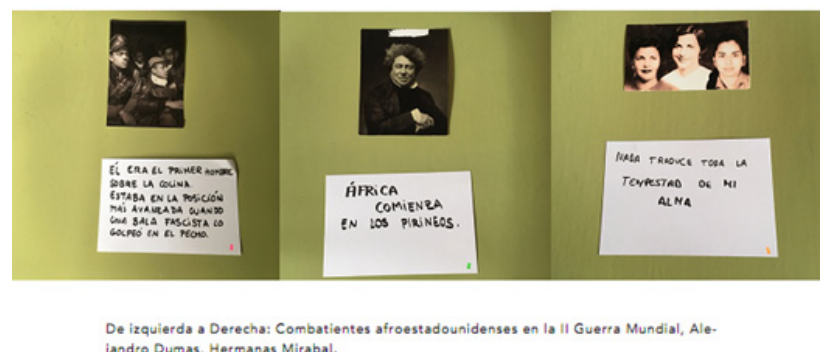
jandro Dumas, Hermanas Mirabal.

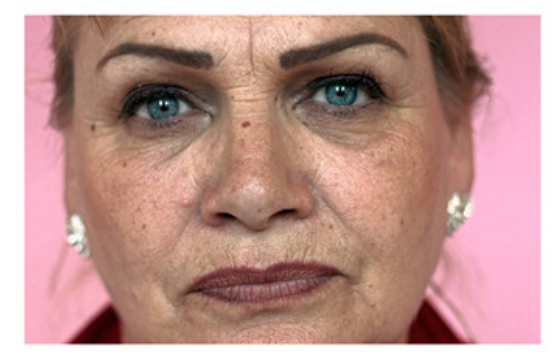

Soraya Post.

Figura 5. Ejemplo de algunos referentes sociales racializados con los que se trabajó en el centro.

No obstante, sí identificaron a algunos de ellos, pero desconocían que se trataba de personas racializadas:

“Una vez más, la clase me sorprendió: pudieron identificar a varios de los referentes históricos y explicar quiénes fueron. Algunos de los referentes les habian permanecido ocultos, o les resultaban conocidos pero jamás se les había dicho que no eran blancxs.

(...) Pero, sobre todo, me reconfortó poder reconocerme en aquellxs que confesaron con los ojos brillantes de emoción que no sabian que (por ejemplo) 
Charles Chaplin no era payo, o que Alejandro Dumas no era blanco. Me reconfortó saber que lo que estábamos haciendo no era una pérdida de tiempo, que las horas extra en la oficina para poder estar ahi el viernes con ellxs lo merecian, que entre ellxs habría alguien no muy distintx a mi yo adolescente." (Victoria)

Y en relación con los referentes cercanos se desarrolló una dinámica con la siguiente finalidad:

“En esta última sesión queríamos ofrecer a lxs estudiantes referentes racializadxs cercanxs, personas conocidas que, de una forma u otra, están desarrollando un trabajo local de empoderamiento desde su posición.

Contactamos, pues, con personas accesibles y que querían compartir con lxs estudiantes sus distintas experiencias educativas, asi como sus propias historias de cómo habian llegado a situarse en su carrera profesional." (Unidad Didáctica)

Como resultado de esta actividad se constató que el nivel de presencia de estas personas generó interés en el alumnado especialmente porque desde sus posiciones profesionales y experiencias influyó en que se crearan expectativas alcanzables en el alumnado. Ejemplo de ello se muestra en el siguiente comentario:

"Recuerdo un momento en el que, Rita Bosaho les dijo que era diputada. No se lo podian llegar a creer: ¡una diputada afro, y además había venido a su clase. Más tarde, un chaval de la comunidad gitana se acercó a Antumi, dado que los dos estaban interesados en la historia y la arqueología; Angelica Dass también sirvió de referencia para lxs chavalxs que querian dedicarse a profesiones creativas." (Yeison)

Finalmente, también quedaron manifiestas las percepciones para alguno de los miembros del equipo de lo que puede implicar la presencia/ausencia de personas racializadas en el ámbito educativo, como, por ejemplo, la falta de profesionales racializados en el ámbito educativo, así como el estigma que en ocasiones el profesorado otorga al alumnado racializado:

"No puedo negar los nervios que me invadian el cuerpx. Mi cuerpx es un texto y es leído e interpretado de muchas maneras. Un cuerpx no binario, feminizadx, rarx, frente a muchas miradas de complicidad, de extrañeza también. Soy consciente de ello y me pregunté “¿cuántas veces tuve unx profesorx negrx disidente sexual frente a mis ojos?" Y esto no lo digo buscando heroicidad, sino resaltando la violenta construcción del mundo y nuestras referencias de aprendizajes marcadas por la blanquitud y la cis-heterosexualidad." (Yos)

“(...) no dejé de reflexionar sobre el encasillamiento injusto que hace en muchos casos el personal docente a sus estudiantes, y en cómo tantas veces especialmente a lxs alumnxs racializadas o migrantes." (Patricia) 


\subsection{La propuesta educativa}

Respecto a la implicación y participación del alumnado desde un primer momento se muestra colaborativo y con muy buena predisposición al desarrollo de las actividades de clase. Además, la satisfacción de la experiencia es positiva para todos los participantes:

"En nuestra experiencia en el IES PRADOLONGO, lxs estudiantes nos contestan sin dudar que quieren formar parte de este proyecto.

(...) El grupo con el que estuvimos se mostró comprometido, creativo, participativo y trabajador y respondió muy bien a todas las actividades que se propusieron en los talleres, incluyendo la primera en la que les robamos todo el tiempo de su pausa de recreo. Estaba formado por alumnxs racializadxs y no racializadxs, y tantos unxs como otrxs mostraron motivación constante durante el desarrollo de las sesiones." (Afronteriz*s)

Los contenidos de trabajo abordados en la propuesta educativa supusieron un antes y un después para el alumnado por tratarse de focos de atención totalmente novedosos para ellos, especialmente al ser tratados desde el ámbito educativo formal:

"La respuesta de nuestros talleres por parte del conjunto de lxs estudiantxs ha sido muy positiva. El estudiandatado nos mostró su agrado por nuestro proyecto y nuestra presencia en el centro, especialmente lxs alumnxs racializadxs, quienes nos expresaron que nunca antes habian tematizado sus identidades raciales en clase de forma positiva." (Afronteriz*s)

La adquisición de conocimientos a lo largo de las diferentes sesiones favoreció que tuvieran un concepto más positivo de las personas racializadas y lejano al significado que se le otorga desde el imaginario social colectivo:

Por nuestra parte, hemos observado cómo sesión a sesión han ido, efectivamente, reafirmando su identidad racial, llegando algunxs a decidir formar parte activa de sus comunidades.

Asimismo, tanto el resto de compañerxs no racializadxs como la profesora (que facilitó la posibilidad de llevar a cabo estos talleres y estuvo presente en cada momento, proporcionándonos toda la ayuda que necesitásemos), se mostraron igual de interesadxs e hicieron aportes interesantes en las reflexiones a las que llegamos en conjunto sobre los distintos ámbitos de actuación del racismo y participaron activamente en rondas de discusión o en las actividades propuestas". (Afronteriz*s)

Para la profesora también resultó ser una propuesta educativa muy favorable:

"La tutora incluyó en la Memoria anual del curso una valoración muy positiva de la actividad e informó al resto del equipo educativo cuáles habian sido los resultados de la propuesta." (Afronteriz*s) 
Finalmente, para los miembros del equipo Afronteriz*s también tuvo un alcance muy positivo del que también aprendieron:

"La experiencia con lxs alumnxs resultó ser muy enriquecedora para nosotraxs, aprendimos mucho del trabajo con lxs estudiantes y la docente, que estuvieron muy implicados en el proceso, que fueron pacientes y entregadxs en todas las actividades, y siempre, propositivxs, incorporando algunxs de los contenidos a su práctica habitual en el aula, componiendo relatos o temas musicales, algunxs de ellxs incluso actuaron en el Festival AfroConciencia, brindándonos la oportunidad de transmitir la experiencia que habiamos vivido juntxs a otrxs." (Afronteriz*s)

\section{Conclusiones}

Las conclusiones a las que se han llegado producto de los objetivos planteados inicialmente, tal y como ha quedado manifiesto, han sido el producto de un trabajo y una experiencia enriquecedora para todas las personas participantes en la propuesta educativa desarrollada, donde, efectivamente, entre los estudiantes y el centro, y el equipo de educadoras y la institución Matadero, ha sucedido el co-aprendizaje.

Respecto al primer objetivo, las percepciones expresadas por el alumnado relacionadas a sus experiencias vitales en conexión con la racialización, podemos decir que han sido diversas y con una alta carga emocional. Además, se ha favorecido una mayor profundización en la reflexión sobre estas cuestiones y las consecuencias que de ello se desprenden en la cotidianeidad personal, facilitando la verbalización del conflicto y la detección de los imaginarios discriminatorios, aportando herramientas que nos permitan abordar con una mayor resilencia situaciones dolorosas o violentas.

En relación al segundo objetivo, se puede afirmar que la propuesta educativa ha tenido éxito al considerar que se han alcanzado los objetivos previstos. Todos los agentes que han participado reconocen haber aumentado sus conocimientos a raíz de esta experiencia, un mayor conocimiento de los estereotipos raciales, los referentes históricos y actuales o los artistas afrodescendientes y sus contranarrativas.

Se pueden identificar como puntos fuertes los siguientes:

- La actitud, muy positiva, tanto del estudiantado como de la docente hacia las tareas propuestas. Además, se ha mantenido un alto grado de implicación, respeto, participación y compromiso en todas las sesiones, así como un intercambio fluido entre el centro y el equipo de trabajo fundamentado en la confianza, la curiosidad y la escucha.

- El alumnado se ha sentido escuchado y comprendido, ya que se han tratado temas que habitualmente no son abordados en el contexto académico, así como por el hecho de que los contenidos (o muchos de ellos) pueden conectar directamente con sus propias experiencias cotidianas, por encontrarse muy vinculados a una dimensión social y afectiva, elementos clave durante la adolescencia. 
- La creación de un equipo multidisciplinar, diverso, implicado, numeroso, formado fundamentalmente por personas de la comunidad afrodescendiente, en el que también participaron dos personas blancas.

- La aportación de contranarrativas, que lejos de plantear el escenario del conflicto como irresoluble proponen alternativas que nos permitan afrontarlo desde las lógicas del arte o la toma de conciencia sobre el cuerpo como herramientas para el desarrollo personal.

Como elementos a mejorar en la propuesta:

- Poder extender en el tiempo el programa implementado con la intención de ahondar en los contenidos propuestos y profundizar en la investigación a largo plazo.

- Contar con la participación de más profesorado en el centro e interconectar los diferentes grupos, proponiendo también una mayor participación de las familias racializadas como portadoras de saberes susceptibles de abordarse en el aula.

- Implementar el programa de forma paralela en varios centros, con la intención de difundir estos conocimientos y cotejar casos de estudio específicos para valorar de manera situada los beneficios de esta práctica sobre el desarrollo personal del alumnado y la adquisición de herramientas de intermediación en situaciones de discriminación.

\section{Referencias bibliográficas}

Antoine, Y. (2014): Inventores y científicos negros. Barcelona: Wanafrica.

Anzaldúa, G.; et al (2004) Otras inapropiables: Feminismos desde las fronteras. Escalera Karakola ed. Madrid: Traficantes de sueños.

Blakely, A., Keaton, T. D., et al. (2012) Black France: The History and Politics of Blackness. London: Duke University Press

Cebrián, A., García-López, Y., Piña, Y., Rocu, P., et al. (2018) Afronteriz*s: una experiencia de co-aprendizaje. Ed: Matadero Madrid, Madrid.

Cebrián, A. (2015) Etnoeducación y Artivismo: aplicaciones de la educación artística contemporánea no formal en el colectivo afroespañol. Tesis Doctoral: Dpto. Didáctica de la Expresión Plástica. Bellas Artes UCM. Recuperado: https://eprints.ucm.es/41171/ Anexo: https://es.scribd.com/document/362019276/BLACK-IS-BEAUTIFUL-materialadjunto-tesis-doctoral

Martínez, M. (2000). La Investigación Cualitativa Etnográfica en Educación. M é x i c o, D. F.: Editorial Trillas.

Onghena, Y. (2014) Pensar la mezcla. Un relato intercultural. Barcelona: Gedisa.

Ortiz, F. (2002). Contrapunto cubano del tabaco y el azúcar. Madrid: Cátedra.

Serbin, S. (2017): Reinas de África y heroínas de la diáspora negra. Barcelona: Wanafrica.

Sos Racismo. (2017). Informe SOS Racismo 2017. Madrid: Sos Racismo. 